\title{
DIGITALIZATION DRIVEN PUBLIC SERVICE AND SERVICE DELIVERY: THE NIGERIA'S EXPERIENCE
} https://doi.org/10.47743/jopafl-2021-22-05

\author{
Chinedu OFOMA \\ Department of Public Administration, \\ Federal University Lokoja, \\ Kogi State, Nigeria \\ chinedu.ofoma@fulokoja.edu.ng
}

\begin{abstract}
Digitalization is greatly impacting on governance as it has provided a more effective and robust avenue for driving governance processes to achieve optimum results. It is fundamental and strategic to public service in meeting the modern day expectations of the citizens towards quality service delivery. This paper is designed to examine the digital technologies and tools used by various Ministries, Departments and Agencies of Nigeria in delivering services to the citizens. The paper is qualitative because data used were sourced through secondary means such as government MDAs and published articles/works. The data were analyzed using analytical method and found very relevant to the study. The findings of the paper revealed that prior to the introduction of digital technologies in Nigeria public service, service delivery to the citizens was very poor, ineffective and inefficient. It was therefore conclusively stated that the digitalization driven processes in the public service should be sustained but there is need to bridge digital divide among the citizens through policies that would ensure the installation and expansion of content on wired and wireless public networks across the country; and adoption of public-private partnership model aimed at training the citizens, especially rural dwellers on the use of digital technologies.
\end{abstract}

Keywords: Digitalization, Public Service, Service Delivery and Nigeria

\section{Introduction}

Globally, the raison détre for government is the provision of goods and services to the citizens satisfactorily. Egugbo (2020) observed that government across the world has been in constant search aimed at delivering services effectively and efficiently to the public. The result of this was introduction and implementation of so many reforms in the public service. The combination of technical, financial and structural challenges of public service have led to poor service delivery among other negative outcomes (Panayotou cited in Egugbo, 2020). This therefore warranted the need for the use of digital technologies and tools in service delivery. The adoption of digital mechanisms to strengthen service delivery system especially in Africa has taken a national dimension. Evans and Schmalenseee cited in Steur and Seiter (2021) observed the growing interest and enthusiasm in digital technologies in research and practice across the world. Ministries, donors, and implementing agencies have intensified their efforts in finding ways to harness the power of digitalization (Agarwal et at cited in United States Agency International Development, 2020). According to Aker (2017), when it comes to public service delivery, digital technology has the potential to enhance citizens' access to public information, facilitate data collection to ensure proper allocation of public goods and increase access for financial services through mobile money. Digitalization has provided significant opportunity for public service across the globe to enhance service delivery and increase the level of 
transparency as well as boost the citizens' confidence about the system (United Nations Conference on Trade and Development, 2021).

\section{Conceptual clarification}

\section{Digitalization}

Most of the debate on digitalization and development has centered on the degree to which countries across the world have affordable access to various digital tools and their usage (UNCTD, 2020). Digitalization is a complex socio-technical phenomena and procedures of adopting and utilizing digital technologies and innovations by individuals, organizations, and the society at large. Through digitalization, creation of turbulent and competitive environments through rapid headways has been made possible thereby making digital business models to be at advantage (Agbeko, Effah and Boateng, 2021). The expansion of digital data and platforms can create many new development opportunities. Digital data can be used for development purposes and in solving societal problems, including those related to achieving the Sustainable Development Goals. It can thereby help to improve economic and social outcomes and be a force for innovation and productivity growth. The infrastructure provided by platforms can enable more effective connections, transactions, exchanges of information and networking (UNCTD, 2020:5)

\section{Public Service}

Public service is the machinery of government used to formulate and implement public policies and programs for the citizens. It is a conveyor belt through which government presence is felt by the citizens as it translates government policies into tangible services. Fundamentally, public service exists to serve the purpose of service delivery and such services should meet the needs of the citizens (Shittu, 2020). In Nigeria, public service includes Ministries, Departments and Agencies (MDAs) among others which are mainly responsible for converting government policies into tangible services. Since the term "public" according to Jones cited in Shittu (2020) refers to the citizens of a particular geography at a particular time, public service evokes the thought of government involvement in service delivery that is devoid of profit motives. Obikeze cited in Egugbo (2020) submitted that public service is put in place to carry certain functions to the citizens. Nwizu and Nwapi cited in Egugbo (2020) identified the role of public service to include prevention of exploitation, ensuring constant supply of service, prevention of private monopoly and ensuring economic development.

\section{Service Delivery}

Service delivery is the fundamental reason for the existence of public service as its primary role is to provide services which the private sector may not have the capacity to offer or offer them at very high prices to the citizens (Olowu cited in Egugbo, 2020). Public service delivery is sacrosanct as it is a representation of basic structure of nation-building. It is a nexus as well as bond between government and citizens and promotes the values of nations among the citizens (Walle and Scott cited in Shittu, 2020). To Ogunna cited in Shittu (2020), the desire to satisfy the public through the implementation of public policies, enforcement of laws, and realization of public welfare culminates the effective public service delivery. 
Service delivery has been an old concept which draws attention of organizations to their responsibility to render service to their customers, in the most satisfactory manner. The terminology varies depending on the time, place or context. The concept presupposes that, in public service, there is contractual relationship between the customer (the public) and the service provider (government agency) which obliges the latter to render service to the former in most satisfactory way, be it in terms of utility, quality, convenience, timelines, cost, courtesy, communication or otherwise. Another presupposition is that just as in business, the customer is regarded as 'king'. Accordingly, in public service delivery, the public is regarded as 'master', and the ultimate judge of performance (Ahmed citied in Egugbo 2020: 75).

\section{Critical examination of digitalization in Nigeria public service}

Prior to the introduction of digital innovations in the Nigeria public service, there was abysmal service delivery characterized by ineffectiveness, corruption and excessive human interface. According to Magbadelo (2020), there is service failure in Nigeria public service which is an indication of bureaucratic delays in processing requisite approval. Public service in Nigeria is akin to inefficiency, corruption and poor service delivery. The first point of call in our public hospitals in Nigeria is the record unit, where patients' files are kept. Right from this point down to the pharmacy where drugs are administered to patients, are characterized by an ineptitude service offering and delay processes. The ineptitude nature and delay have its root in bureaucratic management dimensions of the hospitals. On the account of the bureaucratic tendency, majority of the health-care workers have a poor attitude to work and this has an overbearing adverse effect on quality service to patients and their health systems (Kuye and Akinwale, 2020: 1). Omisore cited in Ajibade and Ibietan (2016) observed that the introduction of reforms in the public service by the administrations of Olusegun Obasanjo (1999-2007) and Yardua/Goodluck Jonathan failed to achieve the objective of quality service delivery. In the words of Ajibade and Ibietan (2016:10-11)

The efficiency of the Nigeria public service has been put to test and it has experienced series of economic, political and structural transformations by various regimes and administrations in the country at one time or the other. The Nigerian public has faced numerous challenges with service delivery since her independence in 1960. Nigeria like any other developing nation of the world has reviewed its service delivery procedures and processes with a view to having better performance and productivity in the public service. The Nigerian government introduced several reforms and strategies to mitigate ineffective service delivery in the public bureaucracy. The history of the public service reforms in Nigeria is dated back to the colonial era, and there have been several reforms targeted at improving the quality of service delivery in the public sector. But the most worrisome part is the fact that many of these reforms did not achieve their purpose and intentions as the country still battles with very high rates of poverty, poor power supply, unemployment, bad rail system, poor road connections and insecurity to mention but a few.

One of the major expectations of Nigerians is to see a public service whose services are almost of cutting-edge standard rendered with a very minimal human interface that will make the presence of the citizens in public offices almost unnecessary. Service delivery basically assumes that there is contractual relationship between the citizens and public 
service which obliges the latter to deliver services to the citizens in most satisfactory manner in terms of utility, quality, convenience, timeliness and communication (Ahmed in Egugbo, 2020). Similarly, Al-Ghazali cited in Shittu (2020) maintained that one of the ways of measuring effective service delivery is the timely and efficient provision of goods and services.

This above therefore brings into focus the need to investigate the various digital innovations in Nigeria public service aimed at delivering quality services. The Federal Ministry of Communications on 16th April, 2013, developed a Government Service Portal whose major objectives were to ensure faster, cheaper, and more personalized and efficient service delivery that citizens and business men and women can access 24 hours a day and seven days a week. The Portal can be accessed in English, French and Spanish and has the capacity to improve efficiency in the delivery of government services to citizens and stakeholders. Many government ministries, departments and agencies have keyed into the trend of digitalization aimed at improving services to the citizens. The government activities are now enabled through digital tools and technologies. Transactions with government agencies and institutions such as Federal Revenue Inland Service, Federal Road Safety Corps, Universities, Polytechnics and Colleges of Education are electronically done with the use of remitta platform. Precisely, Joint Admission and Matriculation Board (JAMB) saddled with the responsibility of organizing and conducting examination into tertiary institutions of the country now carries this all important function digitally (Computer-Based Test) and has also provided "Central Online Support System" which enables the citizens to create a ticket of complaint when the need arises. Schelenz and Schopp (2018) observed that Nigeria, Kenya, and South Africa are the leading countries in African digital evolution and have shown commitment, resilience and are catching up in the global effort to building a digital planet.

Nigeria Customs Service is one of the government agencies whose services are currently mostly driven by digital technologies. Trouble Ticket System has been developed by the Service on its website to enable end-users submit their technical challenges online. Central Help-Desk was also developed among others to enhance the efficiency and effectiveness of Trouble Ticket System. A central team under Central Help-Desk manages trouble tickets by answering end-users phone calls and keeping the end-users informed through SMS and email. Equally, there is E-Transaction monitoring that provides real-time information on electronic trade transactions processing (https://rade.gov.ng/). Increasingly, Nigeria Immigration Service is delivering its services in that direction as there is an Enhanced E-passport which facilitates the electronic application and processing of passport in the country. The reform has made a lot of progress by way of enhancing prompt decision-making, elimination of human interference, effective communication with applicants and efficient payment mechanism. Nigeria Railway Corporation currently has E-Tickets whereby people digitally pick a date for travel after selecting source station, destination state and choosing date. According to Adeyemo (2011), Nigeria is practically moving in the digital direction in its services to the citizens. All the leading financial institutions, education institutions, examination agencies and key government agencies such as Nigeria Customs Service, Nigeria Immigration Service and Nigeria Law School have made reasonable commitment to digitalization through their operations online. Apart from an online platform created by Corporate Affairs Commission which has provided opportunity for registration of companies and businesses without human interface, the 
Commission has provided online Support Centre which is currently available on its CRP. The support ticketing system is designed in a manner that accepts request/complaint and assigns a unique number to it so as to enable the members of the public track the progress and response to their requests/complaints (https://www.cac.gov.ng/).

The Federal Ministry of Communications and Digital Economy developed four (4) key goals to drive the adoption of e-government across all Ministries, Departments and Agencies which in turn enhance service delivery, transparency, accountability and good governance. Consequently, the E-Government Department began the implementation of the following initiatives:

- National E-Government Master Plan: This is a roadmap for the adoption of eGovernment best practices, by all Federal Government Ministries, Departments and Agencies (MDAs) developed in collaboration with the Government of Korea to further promote the fundamentality of e-governance to the nation which is in consonance with the government's direction of leveraging technology for public service delivery.

- $\quad$ Government Service Portal (GSP): This is a platform (services.gov.ng) developed for the provision of easy access to government services. This has enabled the citizens, businesses and foreigners to easily access public services through a one-stop government portal. Also, it has led to a significant improvement in the government processes and effective and efficient service delivery.

- Government Contact Centre (GCC): The Centre provides access for citizens notwithstanding their location, level of literacy or language to get government services/information through calls. The aim is on citizen orientation and simplicity to enable them communicate with the government in a convenient, simple, electronic and barrier-free manner. This has resulted to employment of good number of citizens as well as enhanced the participation of the citizens in public service.

- $\quad$ Open Data Portal: This is an online platform (data.gov.ng) where government MDAs data/information that is not sensitive is made available for public consumption. This enhances transparency and guarantees inclusiveness in service delivery.

- $\quad$ Electronic Document Management System (EDMS): This is one of the ways in which the government has demonstrated its commitment to digitalization. Electronic Document Management System was developed with a view to moving all government documents online. In other words, it was an effort to deepen the application of ICT in all public endeavours. Consequently, there is increased information security, cost reduction and improved access to information among others.

- $\quad$ The E-Government Capacity Building Program: This is an initiative which primarily aimed at establishing the bedrock for the sustainable development and applications of E-governance in all sectors. To this end, more than 2000 public servants have been trained with main focus on institutional transformation and human resources development.

- $\quad$ The National E-Health Strategic Framework: This was developed in collaboration with the Federal Ministry of Health. The framework has enhanced the quality of health care delivery, reduced cost and facilitated access to health related information. 


\section{Digital divide is a challenge}

Ensuring affordable and reliable connectivity for public service delivery in Nigeria has remained a serious challenge to the digital innovations by the government. There is discrepancy in the utilization of digital technologies and tools among the citizens due majorly to income, location and education gap. According International Telecommunications Union (2008), Nigeria like most countries in Africa has witnessed a massive digital divide. For instance, in 2004, the country had a very insignificant number of PCs in that seven PCs were meant for 1, 000 inhabitants. The level of internet connectivity is also low when compared with the population. Gross Domestic Product of 1400 per person is clearly incapable of purchasing PC at a street price and therefore beyond the reach of so many Nigerians (Arikpo, Osofisan and Usoro, 2009). An International Telecommunications Union (ITU) Report, released on May 11, 2008, revealed that there were 10,000,000 Internet users in Nigeria as of March, 2008 which stood at about $7.2 \%$ of a total population of 138,283,240 people (Arikpo, Osofisan and Usoro, 2009).

Nigeria is made up of 36 states and 774 local government areas with about 150 million people have ICT facilities that are limited to urban areas at exorbitant rates, affordable by the middle and upper classes of society, thus making many of the rural and suburban areas unable to fully participate in the emerging information economy. Nigeria falls within the countries with low digital opportunity index scores. The digital opportunity index scores released by International Telecommunication Union revealed that Nigeria was ranked 31 in the African continent with very low score of $0.41,0.03$ and 0.01 for opportunity, infrastructure and utilization respectively. In terms of ownership and access to personal computers (PCs), the National Bureau of Statistics reported that only $4.5 \%$ of the Nigerian population has access to personal computers. Access implies those who either own a pc or can derive benefits from it. According to the report, only $0.9 \%$ of the population can claim ownership of a pc (Ifijeh, Iwu-James and Adebayo, 2016:53).

Table 1 Nigeria’s Monthly Subscriber Technology Data from January-April, 2021

\begin{tabular}{|l|l|l|l|l|l|}
\hline \multirow{4}{*}{ Active Lines } & Operator & Jan-21 & Feb-21 & Mar-21 & Apr-21 \\
\cline { 2 - 6 } & Mobile (GSM) & $199,863,827$ & $195,734,667$ & $192,081,282$ & $188,375,282$ \\
\cline { 2 - 6 } & $\begin{array}{l}\text { Mobile } \\
\text { (DCMA) }\end{array}$ & - & - & - & - \\
\cline { 2 - 6 } & $\begin{array}{l}\text { Fixed Wired/ } \\
\text { Wireless }\end{array}$ & 105,002 & 105,386 & 105,480 & 105,861 \\
\cline { 2 - 6 } & Volp & 245,165 & 238,441 & 226,851 & 224,591 \\
\cline { 2 - 6 } & Total & $\mathbf{2 0 0 , 2 1 3 , 9 9 4}$ & $\mathbf{1 9 6 , 0 7 8 , 4 9 4}$ & $\mathbf{1 9 2 , 4 1 3 , 6 1 3}$ & $\mathbf{1 8 8 , 7 0 5 , 7 3 4}$ \\
\hline & Mobile (GSM) & $299,252,182$ & $298,872,860$ & $297,536,702$ & $295,765,970$ \\
\cline { 2 - 6 } & $\begin{array}{l}\text { Mobile } \\
\text { (DCMA) }\end{array}$ & - & - & - & - \\
\cline { 2 - 6 } & $\begin{array}{l}\text { Fixed Wired/ } \\
\text { Wireless }\end{array}$ & $\mathbf{2 1 6 , 8 1 4}$ & 216,828 & 217,485 & 216,843 \\
\cline { 2 - 6 } & Volp & $1,068,730$ & $1,069,925$ & $1,069,008$ & $1,069,261$ \\
\cline { 2 - 6 } & Total & $\mathbf{3 0 0 , 5 3 7 , 7 2 6}$ & $\mathbf{3 0 0 , 1 5 9 , 6 1 3}$ & $\mathbf{2 9 8 , 8 2 3 , 1 9 5}$ & $\mathbf{2 9 7 , 0 5 2 , 0 7 4}$ \\
\hline
\end{tabular}




\begin{tabular}{|l|l|l|l|l|l|}
\hline Teledensity & & 104.89 & 102.72 & 100.80 & 98.86 \\
\hline
\end{tabular}

Source: Nigerian Communications Commission Reports (2021) compiled by the Author

\section{Materials and methodology}

The paper adopts a qualitative research method and data were sourced from secondary means including relevant journals and internet resources with a view to finding out the degree of quality service delivery in the Nigeria public service using digital technologies and tools.

\section{Conclusion}

The above discussion has clearly shown various digital innovations in Ministries, Departments and Agencies in Nigeria. The application of digital technologies and tools in the Nigeria public service has significantly improved service delivery by drastically minimizing the level of human interface, making the system more open, reducing cost and strengthening feedback mechanisms between the government and citizens. Notwithstanding, the gains recorded due to introduction of digital innovations and mechanisms, digital divide is acknowledged as a major challenge in delivering services to the public. There are widespread gaps in telephone subscription and internet penetration among the citizens in the country.

Therefore, the government should come up with policies that would ensure the installation and expansion of content on wired and wireless public networks across the country. Equally, there is need for public-private partnership model which would enable the training of citizens, especially rural dwellers on the use of digital technologies and tools. All these will increase the benefits associated with digitalization.

\section{References}

1. Adeyemo, A.B (2011). E-government implementation in Nigeria: An assessment of Nigeria's global e-gov ranking. Journal of Internet and Information System 2(1), 11-19. https://doi.org/10.5897/JIIS.9000007 2. Agbeko, M.N. et al. (2021). Digital transformation initiative in a public sector organization: Stakeholder viewpoints and responses in Ghana. Proceedings of the 54th Hawaii International Conference on System Sciences.

3. Ajibade, O and Ibietan, J. (2016). Public bureaucracy and service delivery in Nigeria: The neoweberian explanation. The Public Administration and Social Policies Review VIII, 2(17). http://eprints.federalpolyilaro.edu.ng/id/eprint/1340

4. Aker, J. C. (2011). Dial "A" for agriculture: A review of information and communication technologies for agricultural extension in developing countries. Agricultural Economics, 42(6), 631-647. https://doi.org/10.1111/j.1574-0862.2011.00545.x

5. Arikpo, I.I. et al (2009). Bridging the digital divide: The Nigerian journey so far. International Journal of Global Business, 2 (1), 181-204.

6. Egugbo, C.C. (2020). Public service delivery in Nigeria's fourth republic: issues, challenges and prospects for socio-economic development. Journal of Public Administration, Finance and Law, 17.

7. Ifijeh, G. et al (2016). Digital inclusion and sustainable development in Nigeria: The role of libraries. 3rd International Conference on African Development Issues (CU-ICADI 2016).

8. International Telecommunication Union (2006). World ICT Development Report. ITU: Geneva, Switzerland. 
9. Kuya, O.L. and Akinwale O.E. (2020). Conundrum of bureaucratic processes and healthcare service delivery in government hospitals in Nigeria. Journal of Humanities and Applied Social Sciences. https://doi.org/10.1108/JHASS-12-2019-0081

10. Lupu, D. (2019). Cost-benefit analysis for transport infrastructure projects: Eastern european cases. Journal of Public Administration, Finance and Law, (15), 107-123.

11. Magbadelo, J.O. (2020). The problematic of service delivery in the Nigerian federal civil service. Annals of Social Sciences and Management Studies.

12. Nigerian Communications Commission Reports (2021). Nigeria’s Monthly Subscriber Technology Data from January-April, 2021.

13. Schelenz, L., \& Schopp, K. (2018). Digitalization in Africa: Interdisciplinary perspectives on technology, development, and justice. International Journal of Digital Society, 9(4), 1412-1420.

14. Shittu, A.K. (2020). Public service and service delivery. Farazmand (ed.), Global Encyclopedia of Public Administration, Public Policy, and Governance, https://doi.org/10.1007/978-3-319-31816-5_4005-1

15. Steur, A.J. and Seiter, M. (2021). Properties of feedback mechanisms on digital platforms: an exploratory study. J Bus Econ 91, 479-526. https://doi.org/10.1007/s11573-020-01009-6

16. United Nations Conference on Trade and Development (2020). Digital platforms and value creation in developing countries: Implications for national and international policies.

17. United Nations Conference on Trade and Development (2021). Digital economy report 2021: Crossborder data flows and development: For whom the data flow. Creative Commons Attribution - Non Commercial - No Derivatives 4.0 International License. 